\title{
COVID-19, ARTE Y CULTURA: CREAR, CONSTRUIR Y GENERAR NUEVAS REALIDADES DESDE EL ARTISTA ${ }^{1}$
}

\section{COVID-19, ART AND CULTURE: CREATE, BUILD AND GENERATE NEW REALITIES FROM THE ARTIST}

\author{
Ana Colomer Sánchez \\ Universidad Antonio de Nebrija, España \\ ORCID: 0000-0002-8056-6797 \\ ana.colomer.universidad@gmail.com
}

(c) (1) 8

| Resumen | Ante la situación vivida por la actual pandemia producida por la COVID-19, la cultura vive un periodo de adaptación en la forma de crear, transmitir y compartir que ha repercutido en nuevos hábitos de consumo y enseñanza en lo social y humano. Esto ha surgido gracias a la constancia de los artistas que persisten y buscan nuevas fórmulas ante el problema existente. Así, en el presente debate, se refleja la visión en primera persona de situaciones reales surgidas en la cultura y el arte; todo ello se nutre además con las entrevistas de dos personalidades relevantes, la Directora de Cultura y Patrimonio de la Generalitat Valenciana, y escritora, Carmen Amoraga y el Catedrático de pintura José María Albareda, que refuerzan el relato. De esto se desprende que la creatividad ha otorgado nuevos escenarios a las artes y la cultura, donde la enseñanza y la difusión han predominado de manera telemática perdurando como alternativa junto con otros recursos. En conclusión, la cultura ha sido uno de los puntos de unión y cohesión social que nos ha acercado a los demás y debe reconocerse como parte productiva de nuestra economía.

Palabras clave: Pandemia, Artes escénicas, Creatividad, Educación online, Crisis cultural.

Abstract | Faced with the situation experienced by the current pandemic produced by COVID-19, culture is going through a period of adaptation in the way of creating, transmitting and sharing that has had repercussions on new consumption and teaching habits. This has come about thanks to the perseverance of artists who persevere and seek new formulas in the face of the existing problem. Thus, this debate reflects the first-person vision of real situations that have arisen in culture and art, nourishing the debate with interviews with two relevant personalities: the Director of Culture and Heritage of the Generalitat Valenciana and writer Carmen Amoraga and the Professor of Painting José María Albareda. Both of them have reinforce the story in the first person. From this, it is clear that creativity has given new scenarios to the arts and culture, where teaching and dissemination has predominated in a telematic way and that it will endure as an alternative towards others resources. In conclusion, culture has been turning points and social cohesion, bringing us closer to others and recognising it as a productive part of our economy.

Keywords: Pandemic, Performing Arts, Creativity, Online Education, Cultural Crisis

' Recibido/Received: | |/06/202|

Aceptado/Accepted: 18/06/202I 


\section{| Introducción |}

La COVID-19 es una pandemia mundial que ha puesto en jaque a las sociedades y economías más sólidas. Presente en 124 países (Emanuel et al., 2020) y con una propagación vertiginosa en España (Organización Mundial de la Salud [OMS], 2020), este virus ha tenido un efecto negativo importante no solo a nivel económico sino también en el sector de la cultura que se ha visto muy castigado. Esto ha provocado algunas acciones como el denominado "parón cultural”.

La situación actual en el terreno del arte y la cultura ha propiciado que los artistas tengan que buscar nuevas formas de compartir, enseñar y crear sus obras, así como otros procesos creativos. El presente debate tiene como finalidad explicar cómo se ha mitigado esta circunstancia frente a la COVID-19 por parte del sector cultural y artístico, así como el uso de la creatividad como herramienta para alcanzar nuevos caminos. Esta cuestión se aborda desde una perspectiva personal como profesora e investigadora de las artes escénicas, contrastada con la visión de personalidades relevantes del mundo de la cultura. A través del formato de la entrevista abierta que enriquece este discurso, se recoge la opinión de Carmen Amoraga, Directora General de Cultura y Patrimonio de la Generalitat Valenciana y escritora nominada a los Premio Nobel, y de José María Albareda, Catedrático de pintura y Premio BBVA, entre otros reconocimientos. El debate se estructura en su desarrollo a partir de cuatro propuestas en torno a la repercusión del COVID-19 en el mundo del arte y la cultura: la primera se refiere a la creatividad y el proceso creativo del artista, la segunda sobre el cambio que ha supuesto la pandemia y cómo afecta a los actos culturales, después la nueva percepción de un mundo cambiante y su repercusión en la educación, por último, una reflexión sobre los puntos anteriores ante la crisis cultural.

\section{| La creatividad y el proceso creativo del artista |}

En este contexto peculiar, donde la pandemia de la COVID-19 ha provocado un bloqueo humano (físico y psicológico) y ha trastocado por completo el planteamiento de la vida tanto a nivel profesional cómo personal, se ha notado la necesidad de adaptarnos al presente y buscar nuevos caminos ante la realidad, pero ¿cómo se ha afrontado? Principalmente, por nuestra capacidad de supervivencia y de resolución ante las dificultades activando estrategias como la creatividad con " $c$ ” minúscula, aquella que todos poseemos en mayor o menor medida y que nos permite resolver los problemas cotidianos (Kaufman y Beghetto, 2009). Teniendo en cuenta esta circunstancia en una situación de pandemia, el desarrollo de estas capacidades ha aumentado, siendo una oportunidad para explorar nuevos horizontes y generar acciones creativas (Mercier et al., 2021).

Ligado al término de creatividad está la palabra resiliencia: la capacidad que tiene la humanidad de afrontar las adversidades, superarlas y transformarlo en una experiencia SHJ, 202I, I (I), pp. 238-248. ISSN: 2792-3967 
positiva (Grotberg, 2006). Esta adversidad, en concreto, se refleja en estar sumido en una pandemia; como consecuencia de ello, el gobierno de España adoptó la medida excepcional del toque de queda reflejado en el BOE (14 de marzo de 2020), que implicaba un periodo de confinamiento domiciliario y posteriormente un control de movilidad y distanciamiento social. Como consecuencia, hemos tenido que modificar los comportamientos personales y laborales.

En el ámbito educativo, como profesora en la parte práctica, he sustituido las clases presenciales actualmente impartidas de manera online; también han sufrido una transformación los espectáculos y creaciones (Villasmil, 2020) porque estos se han visto y gestado en espacios como los salones de las casas. Por todo ello, el hogar es el nuevo escenario de principios del S. XXI, observándose que el arte no se puede limitar a espacios concretos teatros, museos, galerías, sino que puede llegar a otros lugares como ciberespacios (Dueñas-Silva, 2021). Esta sería una de las primeras transformaciones vividas y que ha sido una tendencia en el mundo entero: las casas convertidas en lugares de trabajo y generadores de arte. Destaco positivamente este hecho de poder llegar a todos los lugares del mundo de forma telemática; por el contrario, el artista se ha visto privado del contacto diario, del tú a tú lo que ha aumentado la soledad y la incertidumbre. Experimentar estos sentimientos nos ha obligado a salir del área de confort y tener que buscar nuevos caminos para llegar al público y, de esta forma, poder transmitir los conocimientos mediante otras vías (Zuloaga, 2020).

Una cuestión necesaria que se ha replanteado en la era del teletrabajo es la necesidad de reinventar las clases de danza y qué entrenamientos son posibles teniendo en cuenta factores como el espacio, la comunicación y la retransmisión. En cuanto al primer factor, hemos podido adentrarnos en la privacidad del hogar de Tamara Rojo en Londres, que desde su cocina imparte clases de danza y organizaciones como Movement Research, que nos ofrecen entrenamientos semanales. Para afrontar este reto, el espacio ha sido una de las condiciones, una habitación, salón o cocina que simula un aula sin objetos que molesten durante la transmisión, una buena adaptación de ejercicios diseñados para poder realizarse en un espacio reducido y un objetivo pedagógico más genérico. Se busca principalmente la comunicación sin distracciones para el alumno y un lenguaje claro combinando planos generales con planos medios para poder enfatizar y captar mejor la atención de mis receptores. Respecto a las conexiones vía online, estas han aumentado de manera exponencial, $y$ ha sido necesario tener resoluciones rápidas para solventar las incidencias que surgen en cada clase y afrontar cada retransmisión como única e irrepetible. Por lo tanto, la creatividad ha ofrecido nuevas herramientas para afrontar la parte pedagógica y creadora, y los artistas hemos seguido realizando procesos creativos desde un "yo" personal, pero mostrando un lado más íntimo y privado.

Los entrevistados nos han dado su punto de vista ante la situación que vivimos originada por la COVID-19 y cómo los procesos creativos se han visto afectados. Quisiera saber cómo lo han afrontado ustedes en sus diferentes parcelas... 
Mi proceso creativo es siempre solitario, así que el modo de trabajar no ha cambiado. Sí, quizá la percepción del mundo después del impacto de la pandemia. (Amoraga, 2020)

Claro. En mi caso no ha sido especialmente grave, ya que mi labor fundamental ha sido la enseñanza a nivel profesional. Pero los encargos que me hacían han disminuido considerablemente. (Albareda, 2020)

\section{| La nueva normalidad: repercusión en el arte y la cultura |}

Centrándome en aspectos más cotidianos sobre la prevención del virus que conlleva (uso de mascarillas, lavado de manos, distancia interpersonal, cierres perimetrales y de comunidades), es importante señalar la idea de que el ser humano, a todos los niveles, tiene que afrontar un desafío diariamente donde el miedo se esconde en el aire, en un simple estornudo o en una sala no ventilada. Las soluciones generales frente a la situación generada por el virus COVID-19 se resumen en tres: la vacuna, una inmunidad generalizada de la población o un cambio radical de las costumbres de la sociedad (González, 2020). Ante la llegada de las dos primeras soluciones vivimos en la adaptación y en la convivencia con el virus dentro de una realidad modificada en apenas un año, desde el 11 de marzo de 2020, cuando la Organización Mundial de la Salud (OMS, 2020), declaraba la enfermedad del COVID-19 como una pandemia.

El arte y la cultura están en una pausa donde los actos e iniciativas del sector son mínimos y con medidas muy estrictas. Se ha pasado de estar totalmente parados sin ningún tipo de actividad que no fuera de manera telemática a contar con actividades mucho más restrictivas que en otros sectores. La respuesta a esta falta de apoyos se ha traducido en nuevas vías de escape para cubrir el aumento de la demanda por parte del público, eso sí, vía online (Serrano, 2020). La realidad virtual sería una manera de acuñar lo que sucedió los primeros días del confinamiento, produciéndose una gran oferta de cultura de manera gratuita y virtual (Castro-Martínez et al., 2020). Plataformas como Netflix, museos, cantantes y las redes sociales estaban repletas de cultura para poder consumir. Tenemos el ejemplo de Citymuseo galería digital con la premisa de construir espacios durante la pandemia de la COVID-19 que se basa en un espacio para la distribución del arte mediante la web (Enríquez, 2020). Por otro lado, en el cine plataformas como Amazon Prime o Netflix registraron un aumento considerable pero también sufren actualmente un parón en sus series y producciones, la realización de películas, estrenos y festivales (Nobre, 2020). Y en la música, los artistas de teatro y artes escénicas buscan alternativas ante los grandes eventos y producciones artísticas encontrando en el streaming una nueva forma de difusión y recuperación (Aldo, 2020; Téllez, 2020).

El consumo de cultura se ha visto centrado en las tecnologías, siendo la principal herramienta de consumo y de distribución (Legasa, 2020). Al igual que en otros sectores, Internet ha permitido la interacción entre los usuarios por la velocidad, la inmediatez, la SHJ, 202I, I (I), pp. 238-248. ISSN: 2792-3967 
agilidad y la difusión global de la información. Gracias a esta capacidad de interacción, como investigadora documenté, mediante la recogida de información y seguidamente un análisis descriptivo de esta, la repercusión del proyecto Ciclo cultural Nde rógape COVID -19 que se expuso en la semana de la ciencia de la URJC el 5 de noviembre de 2020, con el título "Operación Espectador: nuevo público para la danza en tiempos de pandemia”, en colaboración con la Dra. Patricia Bonnin-Arias y el Dr. Juan Arturo RubioArostegui. Este trabajo fue creado a partir de las medidas de aislamiento social para proteger la salud con relación a la pandemia de la COVID-19.

La Dirección General de Cultura y Turismo del Municipio de Asunción (Paraguay) ofreció de manera online, contenido cultural de las grabaciones de archivo de las obras del repertorio del Ballet Clásico y Moderno Municipal de Asunción acompañado de breves explicaciones de contenido histórico, técnico y estilístico siendo una guía para el espectador. De la experiencia puedo resaltar que los espectadores que consumen cultura habían tenido contacto directo con el baile o bien porque habían bailado o tenían familiares o amigos bailarines. Pero un aspecto significativo es el apartado dedicado a charlas, mesas redondas y conferencias, mayoritariamente bien recibidas por parte de los espectadores, que planteaban la creación de un programa de formación del espectador, siendo partidarios de incluir estos conocimientos de danza dentro del currículum escolar. Se valoró positivamente la utilización de las plataformas digitales para el consumo del arte, pero se prefería poder ir al teatro y espacios escénicos cerrados, entendiendo que esta transformación de la realidad dejará algunas nuevas costumbres. En este sentido, se vislumbra cierta nostalgia hacia lo experimentado con anterioridad predominando lo presencial.

A los entrevistados, ante esta nueva situación, les planteo si realmente asistimos a una nueva realidad en todo el mundo por causa de esta pandemia; no sé si comparten la idea de que, efectivamente, dicha situación afectará al mundo del arte:

Sí. Por un lado, la fuerte crisis económica va a afectar a los creadores y las creadoras puesto que la paralización de los eventos y actividades afecta más a la cultura que a otros sectores productivos. Sin embargo, es cierto también que durante el confinamiento la ciudadanía utilizó la cultura como herramienta de evasión y eso ha cambiado también para ciertos sectores ciudadanos que no tenían acceso a la cultura entre sus prioridades. Hoy por hoy, se ven más colas en los museos que nunca, por ejemplo. (Amoraga, 2020)

Seguro. Ya estamos viviendo una nueva etapa donde la vida cultural está claramente postergada en muchos aspectos. (Albareda, 2020)

Puede pensarse entonces que la manera de entender el arte y la cultura sean diferentes ahora y en un futuro cercano:

Depende de los creadores. Para los que utilizan la realidad como inspiración, sin duda. (Amoraga, 2020) 
Creo que sí. Aún no sabemos los cambios reales porque todavía estamos en pleno proceso pandémico, pero viendo el parón de todo el ámbito cultural de los meses pasados seguro que se producirán importantes modificaciones. (Albareda, 2020)

\section{| Las nuevas tecnologías como herramientas de educación y difusión del arte |}

Al hilo del apartado anterior, la difusión del arte y la cultura ha quedado establecida con la nueva realidad y es mayoritariamente de manera online. La educación ha tenido el mismo camino nada más empezar el estado de alarma en España: el curso escolar 20192020 se vio afectado por un proceso de digitalización, pero sin ningún ensayo previo, maestros y alumnos no estaban preparados para esa transición forzosa. A pesar del reto, la comunidad educativa la afrontó y actualmente se sigue enfrentando al binomio presencial-online. La nueva situación ha tenido que combatir diferentes escenarios que no se pueden cuantificar a nivel de repercusión educativa todavía, pero sí se vislumbran las diferencias socioeconómicas de cada familia y la capacidad de los padres y madres para tener que combinar el trabajo con el colegio de sus hijos/as, la conciliación laboral (Azorín, 2020; Trujillo-Sáez et al., 2020).

Ante esta realidad, como investigadora y artista, realicé, junto a la Dra. Mónica Olalla, filóloga y profesora de literatura, el Proyecto en el aula "La siesta de un fauno". Mallarmé y Nijinsky a través de la danza y de la literatura. El proyecto se iba a realizar de manera presencial en el instituto "Diego Jesús Jiménez" de Priego (Cuenca) en el curso 20192020 y se tuvo que modificar en formato online. El acceso a internet y la carencia de formación ante la educación e-learning, además del extenso currículum de literatura universal y la cumplimentación de objetivos fueron las mayores dificultades en el proceso online; sin embargo, con poco tiempo se llevó a cabo el proyecto (Trujillo- Saéz et al., 2020). La actividad tenía como objetivo el análisis del poema de Mallarmé y un análisis coreográfico de "La siesta de un fauno" de Nijinsky para enriquecer el poema junto a las artes escénicas: era una actividad complementaria para enriquecer el temario.

Se apreció una implicación de los padres y madres quienes aceptaron el proyecto y durante la pandemia aumentaron su vinculación con el profesorado. Padres y madres han sido en gran parte responsables del aprendizaje domiciliario y el alumnado ha afrontado este escenario de manera implicada y responsable destacando una buena tutorización virtual por parte del profesorado (Hernández-Ortega y Álvarez-Herrero, 2021; Trujillo-Sáez et al., 2020). En el proyecto se realizó también un pre-cuestionario para conocer la relación de los alumnos con las artes escénicas y la asignatura de Literatura Universal y un post-cuestionario que medía su grado de satisfacción con el proyecto y la inclusión de la danza en las aulas. 
En el proceso, además, los resultados fueron muy gratificantes ya que el alumnado recibió el proyecto en su totalidad como satisfactorio y lo volverían a realizar utilizando la danza en el aula. Además de la parte teórica se utilizaron grabaciones audiovisuales, videos e imágenes para transmitir los aspectos dancísticos, ya que de manera escrita hubiera sido muy complicado (Blández, 1996). Dichos materiales fueron utilizados para redactar los resultados y las conclusiones, (Colomer y Olalla, 2020). Un nuevo reto que no se había contemplado en el diseño original del proyecto, eran la cámara y los videos, principales herramientas en esta pandemia.

Ante estas cuestiones, a los entrevistados se les plantea si la difusión del arte y la manera de enseñar han cambiado a su parecer:

Las nuevas tecnologías son ya la herramienta principal de difusión. Las galerías ofrecen sus catálogos online. Los museos combinan la presencialidad y la virtualidad. Las presentaciones de libros, otro tanto. Las clases, por supuesto. (Amoraga, 2020)

Ambas partes han cambiado. Hemos asistido a una relevancia de los medios digitales son precedentes. La difusión del arte está en manos de las redes. Y la enseñanza ha tenido que improvisar sobre la marcha un incremento de plataformas y recursos para poder adaptarse a esta situación tan difícil. (Albareda, 2020)

Asimismo, se les pregunta qué opinión tienen sobre la difusión y transmisión de la cultura y del arte mediante internet y si es una herramienta que va a quedarse:

Sí. Va a quedarse y a convivir con la presencialidad. (Amoraga, 2020)

Ya está instalándose de forma permanente. (Albareda, 2020)

En un plano social-económico, la crisis va a tener un gran impacto. En ese aspecto el mundo del arte y la cultura es uno de los más golpeados, por ello quizá el futuro sea diferente:

Lo veo complicado porque todavía no se tiene claro que la cultura es un sector productivo como cualquier otro. No se tiene claro que la cultura tiene un efecto multiplicador en la economía. Organizar una exposición, programar un concierto o una obra de teatro no sólo repercute en artistas, cantantes o actores. También en técnicos, carpinteros, camareros... Eso se debe tener claro. Igual que no se tiene claro que el sector de la cultura supone el $3 \%$ del PIB (el de la automoción es del $10 \%$ y el de la construcción de poco más del $5 \%$ ). La cultura es importante para la economía y mientras eso no se asuma, no vamos a restarle complicación a una situación que en general es complicada y con la pandemia, trágica. (Amoraga, 2020) 
Lo veo muy negro. En mi caso, y en otros ámbitos artísticos es fundamental el contacto directo con la obra. La piel de la pintura es necesario sentirla directamente sin intermediarios. (Albareda, 2020)

\section{| Reflexiones finales respecto al impacto de la COVID-19 y la crisis en el arte y la cultura |}

Las diferentes pandemias vividas con anterioridad supusieron un cambio social y económico. En este aspecto no todos los sectores lo afrontarán de igual manera. La cultura y el arte están postergados y sumidos en una profunda crisis; ante esta situación la UNESCO crea el proyecto Resiliart que tiene como objetivo reflejar el impacto de la pandemia COVID-19 en el sector cultural. Al respecto, Amoraga nos plantea que los creadores y creadoras van a ver un cambio donde la realidad será inspiradora. Por su parte, Albareda nos relata que al vernos inmersos todavía en esta situación y no estar en el periodo de recuperación económica es difícil vaticinar el futuro de las artes y la repercusión que tendrá en un futuro, pero ambos entrevistados tienen claro que hay cambios que han venido para quedarse.

Como resultado de la situación que llevamos mucho tiempo viviendo, nuestros modos de vivir y de disfrutar la cultura están cambiando. El salón de casa lo hemos convertido en el aula de ballet, donde el pianista está en Rusia, el profesor en Londres y el alumno en distintos puntos del mundo. Los artistas hemos respondido gestando soluciones alternativas gracias a la creatividad; así, la cultura ha creado soluciones innovadoras, usando las herramientas digitales para realizar actividades y contactar con todos los públicos (Dueñas-Silva, 2021; UNESCO, 2020).

La difusión de la cultura y la educación vía internet va a ser algo permanente. En la educación se necesitará una actualización metodológica y el profesorado ha mostrado una imagen clara de compromiso dispuestos a un cambio importante en el currículum y la propia metodología de la enseñanza (Aznar, 2020; Azorín, 2020; Cabero-Almenara y Palacios-Rodríguez, 2020; Trujillo-Sáez 2020).

Por otro lado, la cultura nos ha permitido tener una cohesión social, al compartir y vivir actos culturales que nos han hecho estar más cerca de los demás (Castro-Martínez et al., 2020; Zuloaga, 2020). Esta herramienta, unida al fomento de la práctica artística al alcance de todos, ha sido una vía de escape para la sociedad. Desde otra perspectiva también nos hemos acercado a la danza como un punto de unión con nuestro cuerpo y nuestro fluir personal, creando la sensación de "empatía cinestésica" que surge del placer de ver y hacer coreografías, clases de danza, ensayos, así como clases prácticas y teóricas, (Barboza y Jiménez, 2020; Bardet, 2012) todo ello de manera telemática.

Concluyo con dos frases que resumen el camino a seguir ante la crisis existente, por parte de Amoraga "No se tiene claro que la cultura tiene un efecto multiplicador en la SHJ, 2021, I (I), pp. 238-248. ISSN: 2792-3967 
economía" y la de Albareda "Necesitamos que se tome conciencia de la importancia de la cultura, de su relevancia en la vida cotidiana".

El análisis futuro de nuestra realidad ha de ser objeto de reflexión sobre los puntos fuertes que nos permitan mejorar y enriquecernos. Por otro lado, las dificultades que se presentan día a día hemos de verlas como una oportunidad para seguir aprendiendo y compartir experiencias desde distintos campos o perspectivas. Lo interdisciplinar se hace indispensable en este nuevo presente.

\section{Referencias}

Aldo, N. Cuarentena Fest, un festival musical desde el salón de casa. Disponible en <EIPaís.https://elpais.com/espana/catalunya/2020-03-16/cuarentena-fest-un-festivalmusical-desde-el-salon-de-casa.html> (consultado el 17 marzo 2020).

Aznar Sala, F. J. (2020). La Educación Secundaria en España en Medio de la Crisis del COVID-19. International Journal of Sociology of Education, Special Issue: COVID-19 Crisis and Socioeducative Inequalities and Strategies to Overcome them, 53-78. Disponible en http://doi.org/10.17583/rise.2020.5749.

Azorín, C. (2020). Beyond COVID-19 supernova. Is another education coming? Journal of Professional Capital and Community, 5 (3-4), 381-390. Disponible en $<$ https://doi.org/10.1108/JPCC-05-2020-0019>.

Barboza, P. O., y Jiménez, V. D. L. O. (2020). Arte, cuerpo y movimiento a ritmo de COVID: Preguntas sobre la danza desde el encierro. Revista Rupturas, 39-43.

Bardet, M. (2012). Pensar con mover: un encuentro entre danza y filosofía. Editorial Cactus.

Blandez, Á. (1996). Investigación acción un reto para el profesorado. Guía práctica para grupos de trabajo, seminarios y equipos de investigación. Publicaciones INDE.

BOE. núm. 67, de 14/03/2020. Real Decreto 463/2020, de 14 de marzo, por el que se declara el estado de alarma para la gestión de la situación de crisis sanitaria ocasionada por el COVID-19.

Cabero-Almenara, J. y Palacios-Rodríguez, A. d. P. (2020). Metareflexión sobre la competencia digital docente: análisis de marcos competenciales. Revista Panorámica, 32, 32-48. Disponible en <https://hdl.handle.net/11441/101703>.

Castro-Martínez, A., Pérez-Ordóñez, C., y Torres-Martín, J. L. (2020). Eventos musicales online durante la crisis de la COVID-19 en España. Análisis de festivales en redes sociales y de sus estrategias de comunicación. Hipertext. net, 21, 41-56. 
Colomer Sánchez, A. y Olalla Sánchez, M. (2020). Proyecto en el aula: "La siesta de un fauno". Mallarmé y Nijinsky a través de la danza y de la literatura. En Investigación en la danza. Madrid online 2020. Ediciones Mahali.

Dueñas-Silva, S. V. (2021). La creatividad artística en tiempos de pandemia. Dominio de las Ciencias, 7 (1), 677-690.

Emanuel, E. J., Persad, G., Upshur, R., Thome, B., Parker, M., Glickman, A., Zhang, C., Boyle, C., Smith, M., y Phillips, J. P. (2020). Fair allocation of scarce medical resources in the time of Covid-19. New England Journal of Medicine. <https://doi.org/10.1056/NE]Msb2005114>.

Enríquez, L. A. C. (2020). Sobre: Citymuseo galería digital. Construir espacios digitales para el arte durante la Covid-19 (www. citymuseo. com). Revista de Arte Ibero Nierika, $19,227-234$.

Gonzalez Padilla, R. (2020). Covid-19 ¿Cómo recobrar el aliento? Dialektika: Revista De Investigación Filosófica Y Teoría Social, 2 (4), 92-94.

Grotberg, E. (2006). ¿Qué entendemos por resiliencia?, ¿cómo promoverla?, ¿cómo utilizarla? E. Grotberg (Ed), La resiliencia en el mundo de hoy. Cómo superar las adversidades, 17-57. Gedisa.

Hernández-Ortega, J., y Álvarez-Herrero, J. (2021). Gestión educativa del confinamiento por COVID-19: percepción del docente en España. Revista Española de Educación Comparada, 38, 129-150. <https://doi.org/10.5944/reec.38.2021.29017>.

Kaufman, J. C., \& Beghetto, R. A. (2009). Beyond big and little: The four model of creativity. Review of general psychology, 13 (1), 1-12.

Legasa, M. (2018). Otra forma de acceder a la cultura: el consumo online se afianza en la era pospandemia. Uppers. <https://www.uppers.es/cultura-yentretenimiento/arte/consumo-cultura-online coronavirus_18_2953395275.html> (consultado el 28 mayo 2020).

Mercier, M., Vinchon, F., Pichot, N., Bonetto, E., Bonnardel, N., Girandola, F., \& Lubart, T. (2021). COVID-19: A Boon or a Bane for Creativity? Frontiers in psychology, 11, 3916. Disponible en <https://doi.org/10.3389/fpsyg.2020.601150>.

Nobre, G. F. (2020). Las industrias creativas versus COVID-19. Economía Creativa, 13, 171-188. Disponible en <https://doi.org/10.46840/ec.2020.13.07>.

Organización Mundial de la Salud (OMS). (2020). Coronavirus disease (COVID-19) technical guidance: Infection prevention and control / WASH. Disponible en $<$ https://www.who.int/emergencies/diseases/novel-coronavirus-2019/technicalguidance/infection-prevention-and-control>. 
Serrano, N. (3 de marzo 2020). Teatro y conciertos online en el salón de casa. Disponible en $<A B C$.https:/www.abc.es/espana/madrid/abci-teatro-y-conciertos-saloncasa-202004030039_noticia.html>.

Trujillo-Sáez, F.; Fernández-Navas, M.; Montes-Rodríguez, M.; Segura-Robles, A.; Alaminos-Romero, F.J. y Postigo-Fuentes, A.Y. (2020). Panorama de la educación en España tras la pandemia de COVID-19: la opinión de la comunidad educativa. Fad.

Téllez Rubio, J. J. (2020). La cultura contra el Covid-19: hacia un avatar telemático de la realidad. Periférica Internacional. Revista Para El análisis De La Cultura Y El Territorio, (21), 36-43. Disponible en < https://doi.org/10.25267/Periferica.2020.i21.04>.

Villasmil, M. T. (9 de mayo de 2020). Danza en tiempos de Coronavirus. Revista Susyq. Disponible en <https://susyq.es/actualidad/1001-danza-en-tiempos-de-coronavirus>.

Zuloaga, M. L. (2020). Arte, creatividad y resiliencia: recursos frente a la pandemia. Avances en Psicología, 28 (2), 191-204.

\section{| Nota biográfica |}

Ana Colomer Sánchez está doctorada en Arte (2011) por la Universidad Rey Juan Carlos, Madrid (Departamento de Comunicación I, Programa oficial de posgrado en artes escénicas). Forma parte del grupo de Investigación Nebrija en Comunidades artísticas y académicas (Universidad Nebrija). Ha participado como profesora en el Máster de Artes Escénicas (URJC) y en expertos universitarios (UAH). Participa en congresos y conferencias nacionales e internacionales. Contribuye en comités científicos de varias revistas indexadas a nivel nacional e internacional y publica en revistas de impacto incluidas en Web of Science (SSCI) y Scopus, así como es autora de libros y capítulos sobre la metodología de la investigación y la creatividad. Líneas de investigación: creatividad, danza, pedagogía. 